\title{
MODERATE QUALITY OF VOICE TRANSMISSION USING 8-BIT MICRO-CONTROLLER THROUGH ZIGBEE
}

\author{
Ankit Rawat ${ }^{1}$, Sushila Chahar ${ }^{2}$, Himanshu Bhojwani ${ }^{3}$ \\ ${ }^{I}$ M.Tech Scholar, JaganNath University, Jaipur, Rajasthan \\ ${ }^{2}$ Asst. Professor, JNIT, Jaipur, Rajasthan. \\ ${ }^{3}$ Director, Contrivence IT Solution Pvt. Ltd., Jaipur, Rajasthan
}

\begin{abstract}
This paper proposes an integrated approach towards Transmission of Moderate Quality of Voice Signal using 8-bit Microcontroller through Zigbee. Here Zigbee technology is used since it provides seamless addressable connectivity, simple and low cost wireless communication and networking solution for low data rate and low power consumption applications. Generally, Voice over Zigbee prototypes uses high speed Digital Signal Processors or 32- bit Micro Controllers. These prototypes have complex circuitry and are very expensive. Here, in this project we have made a prototype that uses low power 8- bit Micro Controller and Off the Shelf components, which makes it cost effective and easy for production. Because of its cost efficiency and ease of availability of components, it can be easily employed in circuit that uses voice communication. PIC16F876 microcontroller is being here at the transmitter end because of its features such as 10-bit ADC, 8-bit USART. PIC16F73 microcontroller is used at the receiver end because of its features such as 8-bit USART, 8-bit Pulse Width Modulator (PWM). An additional $R-2 R D A C$ is also employed at the receiver end. The project is quite helpful in applications such as home monitoring and automation, environmental monitoring, industry control and emerging low rate wireless sensor applications.
\end{abstract}

Keywords - Zigbee Technology, PIC16F876 and PIC16F73 Micro-Controllers

\section{INTRODUCTION}

Voice over wireless sensor networks has seen a tremendous growth in both business and consumer sectors. Wireless sensor networks are of low cost and consumes less power, thus in this realm we will study how to transmit moderate quality of voice signal using 8-bit microcontroller through Zigbee.

The first and foremost question that comes into mind is that why Zigbee should be considered for audio applications, especially when other alternatives such as Bluetooth, Wi-Fi already cater for such needs?

There are several arguments that goes in favor of Zigbee, at least for a certain category of audio applications:

$>$ Zigbee has a defined data transfer rate of $250 \mathrm{kbps}$ and the data rate required for the transmission of audio signal, mainly varies from tens of kbps to hundreds of kbps, making Zigbee an alternative for low end and mid end applications.

$>$ Zigbee is well suited for transmission of regular, irregular data or a single signal transmission from input device or sensors.

$>$ Zigbee features power saving techniques so that deep sleeps can be handled efficiently with rapid wake up and rapid fall into sleep features. Thus, Zigbee wireless sensors can last for years without change in battery.

$>\quad$ The software size of Zigbee stack is only 1/10 (one tenth) of a Bluetooth stack.
Zigbee technology consists of a suite of specifications designed particularly for wireless network sensor and controllers, based on IEEE 802 standard for personal area network. Zigbee has a defined data rate of $250 \mathrm{kbps}$ suitable for transmission of regular or irregular data from the input device. The name "Zigbee" refers to waggle (to move impatiently) dance of honey bees after their return to their beehives. Zigbee is a cheap, more power efficient, wireless sensor network standard. The low cost feature of Zigbee allows it to be widely employed in wireless control and monitoring applications while the low power consumption feature provides longer life to the equipments.

\subsection{Voice Over Zigbee}

In this section we discuss methodology of how to transmit moderate quality of voice signal using 8-bit micro controller through Zigbee.

\subsubsection{Block Diagram Of Transmitter}

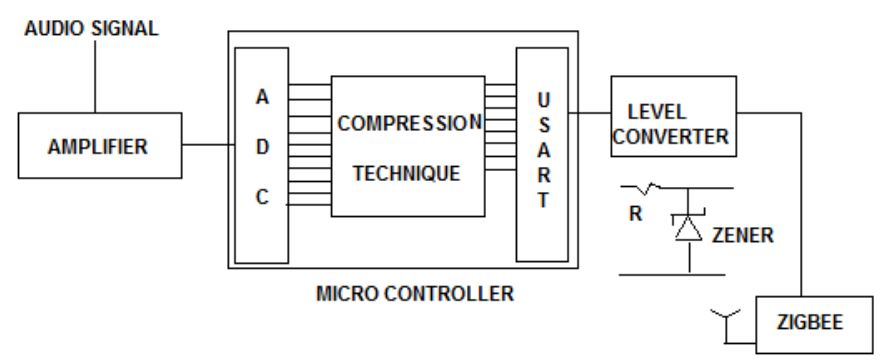

Fig.1.1 - Block Diagram of Transmitter 
The audio signal that is generated, is first fed to the amplifier in order to improve it's amplitude level. The amplified audio signal is than fed to the microcontroller.

The ADC of the controller than converts the analog audio signal into 10-bit digital signal using Pulse Code Modulation (PCM) technique. The 10-bit digital data is than compressed to 8-bit digital data using compression technique. The 8-bit inbuilt USART then converts this 8-bit parallel data into 8-bit serial data. The output of the controller is a $5 \mathrm{~V}, 8$-bit serial data. This data is than fed to level converter, which suppresses the output of the controller from $5 \mathrm{~V}$ to $3.3 \mathrm{~V}$. This is done by using the circuit shown in the Fig. 1.1, where Zener Diode is used as voltage regulator. Level Conversion is necessary since the Zigbee operates at $3.3 \mathrm{~V}$. This serial data, with $3.3 \mathrm{~V}$ amplitude is than fed to Zigbee, which than modulates the given data using Offset-Quadrature Phase Shift Keying (O-QPSK) and then transmit it.

\subsubsection{Block Diagram Of Receiver}

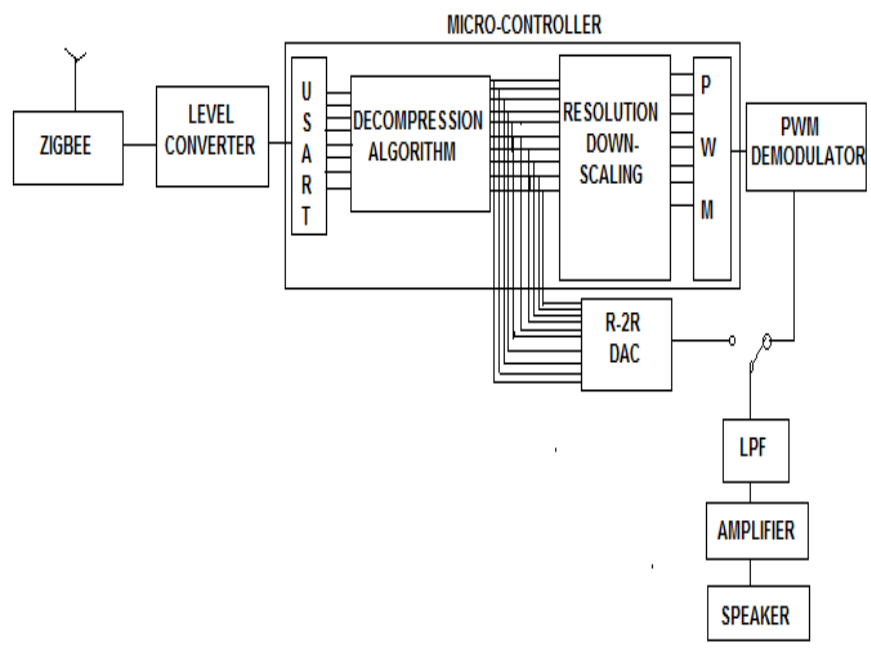

Fig1.2- Block Diagram of Receiver

At the Receiver End, the modulated digital signal is received by the Zigbee. Zigbee than demodulates the received signal, thereby providing digital signal having an amplitude of $3.3 \mathrm{~V}$. Since the micro-controller operates at $5 \mathrm{~V}$, this $3.3 \mathrm{~V}$ signal is converted to $5 \mathrm{~V}$ using MAX $232 \mathrm{IC}(3.3 \mathrm{~V}$ to $5 \mathrm{~V}$ level converter).After level conversion, the 8 -bit , $5 \mathrm{~V}$ serial data is sent at the input of USART, which converts it in 8-bit, 5V parallel digital data signal. The output of USART is than fed to decompression algorithm, which converts input 8-bit data into 10-bit data. This 10-bit data serves two purpose here:

Firstly, this 10-bit data is down scaled to 8-bits, using suitable algorithm. This is done because the PWM modulator is of 8 bits. The 8-bit digital data is than fed to the Pulse Width Modulator.

Secondly, this 10-bit data is given at the input of 10-bit DAC (R-2R DAC being used here).

The PWM output is than demodulated using PWM demodulator. The analog output of PWM demodulator and R-2R DAC is connected to Low Pass Filter (LPF) through a switch. Here, LPF is used to reduce the unwanted signal (noise). The output of LPF is fed to the amplifier, which amplifies the incoming signal. The amplified signal is than fed to the speaker.

\subsection{Hardware Description}

\subsubsection{Hardware Description of Transmitter}

\subsubsection{Power Supply Section}

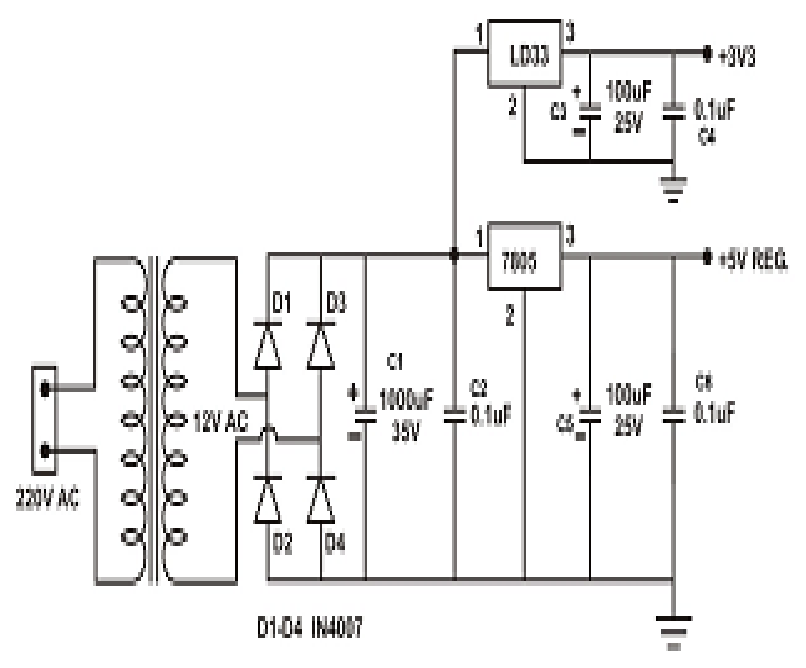

Fig1.3- Power Supply of Transmitter

Here, at the input 220V AC supply is applied. This 220V AC is step down to $12 \mathrm{~V}$ AC using a Step Down Transformer.

The $12 \mathrm{~V}$ AC supply is than applied to Bridge Rectifier which converts it in $12 \mathrm{~V}$ Full Rectified AC signal using diode D1, D2, D3, D4 (1N4007X4). The output of Bridge Rectifier is applied across capacitor $\mathrm{C} 1(100 \mu \mathrm{F}, 35 \mathrm{~V})$, which is acting as main filter capacitor. The output of this capacitor is an unregulated $12 \mathrm{~V}$ DC signal. This unregulated $12 \mathrm{~V}$ DC is applied across capacitor $\mathrm{C} 2(0.1 \mu \mathrm{F})$, which is acting as additional filter capacitor. The purpose of this capacitor is to remove noise from $12 \mathrm{~V}$ DC line.

The 12V DC signal is applied across IC LD33 and IC7805. Both of these are three terminal Voltage Regulator ICs and their output are $3.3 \mathrm{~V} \mathrm{DC}$ and $5 \mathrm{~V}$ DC respectively. Here, capacitor $\mathrm{C} 3(100 \mu \mathrm{F}, 25 \mathrm{~V})$ and $\mathrm{C} 4(0.1 \mu \mathrm{F})$ remove the low frequency and high frequency noise from $3.3 \mathrm{~V}$ DC line respectively. Also, capacitor $\mathrm{C} 5(100 \mu \mathrm{F}, 25 \mathrm{~V})$ and $\mathrm{C} 6$ $(0.1 \mu \mathrm{F})$ remove the low frequency and high frequency noise from 5V DC line respectively. 


\subsubsection{Transmission Section}

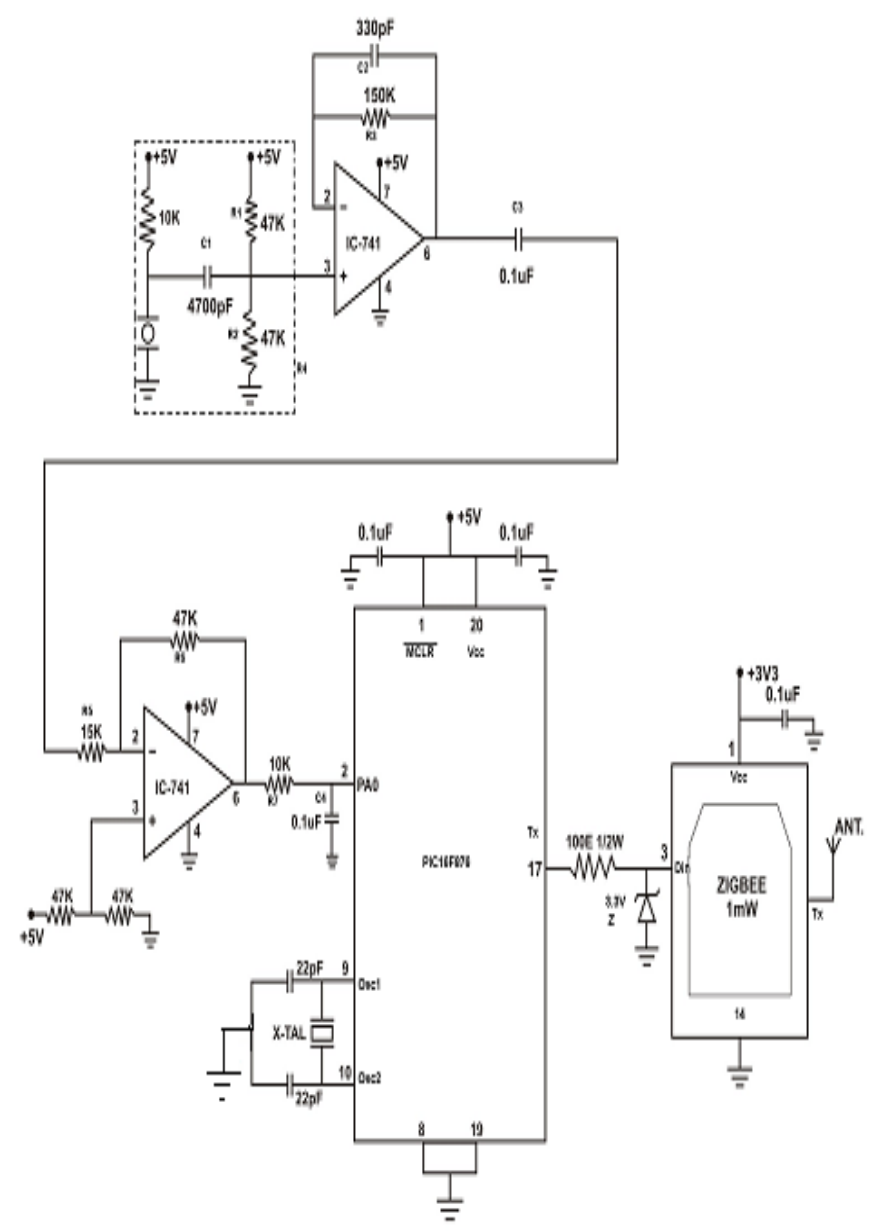

Fig1.4- Transmission Section of Transmitter

At the transmission section, a condenser mic is connected at the input, through the 5V DC supply and $10 \mathrm{~K}$ resistor. This condenser mic is acting as a transducer, which converts the audio signal into the electrical signal. The electrical signal obtained at the output of the mic, is centered across $5 \mathrm{~V} \mathrm{DC}$, whose amplitude varies between few milli-volts, as shown in Fig.1.5

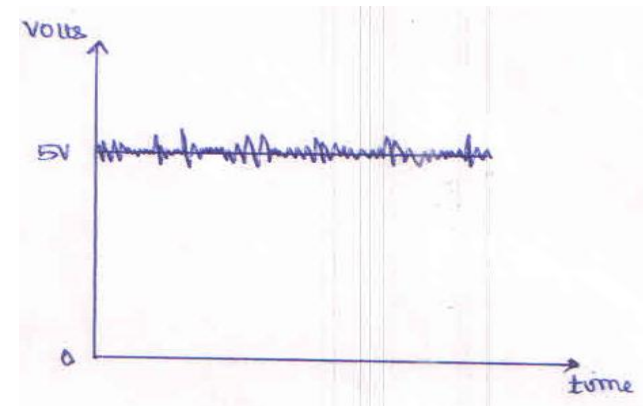

Fig1.5- Audio Signal centered at 5V

This output is than passed through capacitor $\mathrm{C} 1(4700 \mu \mathrm{F})$, which is a coupling capacitor. Thus, this capacitor removes the noise part from the received signal.

The output of the capacitor $\mathrm{C} 1$ is applied across a Voltage Divider circuit consisting of resistor R1 and R2 (47k each).
The purpose of using a Voltage Divider circuit is to shift the reference voltage from $5 \mathrm{~V}$ DC to $2.5 \mathrm{~V}$ DC. This can be shown from Fig.1.6

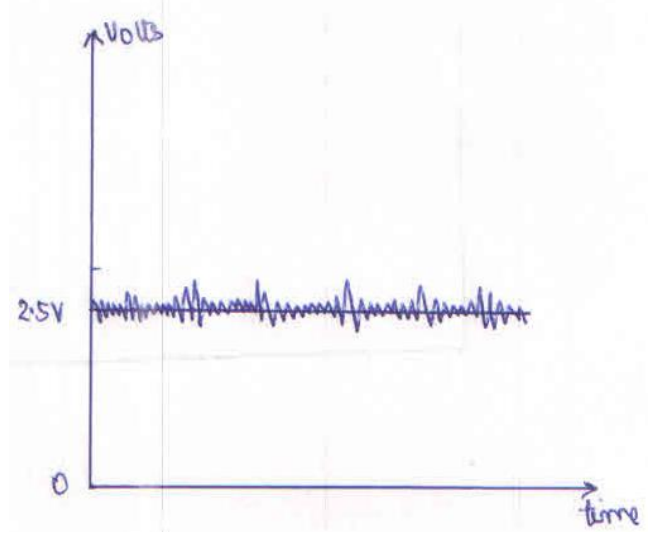

Fig1.6- Audio Signal centered at $2.5 \mathrm{~V}$

The output of voltage divider is than applied to pin 3 (Non Inverting terminal) of OP-AMP1 (IC 741). Here, OP-AMP1 is being used in non-inverting mode since input is applied at the non inverting terminal. In OP-AMP1, 5V DC is connected at pin 7 and pin 4 is grounded. Pin 2 (Inverting terminal) is connected to pin 6 (Output) through a resistor R3 (150k), which provides negative feedback to OP-AMP1.

Also a capacitor C2 (330pF) is applied across pin 2 and pin 6 . The purpose of this capacitor is to prevent oscillation and decoupling the noise. The output of OP-AMP1 would be similar to Fig. 1.7

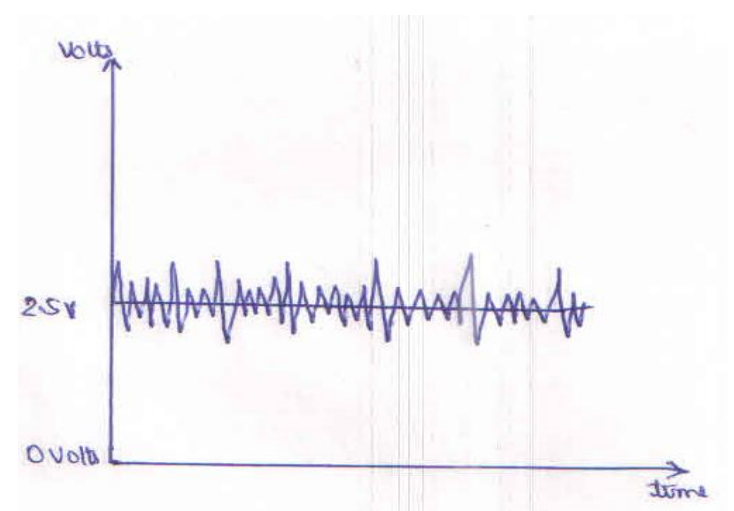

Fig1.7- Amplified Audio Signal centered at 2.5V

The output of OP-AMP1 is than passed through capacitor C3 $(0.1 \mu \mathrm{F})$. The purpose of $\mathrm{C} 3$ is to block all the $\mathrm{DC}$ components and allow pure amplified audio signal.

The output of capacitor $\mathrm{C} 3$ is applied to pin 2 of OP-AMP2 (IC 741) through resistor R5 (15k). Here, OP-AMP2 is being used in Inverting mode since input is applied at the Inverting terminal. In OP-AMP2, 5V DC is connected at pin 7 and pin 4 is grounded. A reference voltage of $2.5 \mathrm{~V}$ is applied to pin 3 of OP-AMP2. Pin 2 of OP-AMP1 is connected to pin 6 through a resistor R6 $(47 \mathrm{k})$, which provides the negative feedback. Here, the output of OP-AMP2 will be an amplified 
audio signal ranging between 0 to $5 \mathrm{~V}$ and centered about 2.5V as shown in Fig.1.8

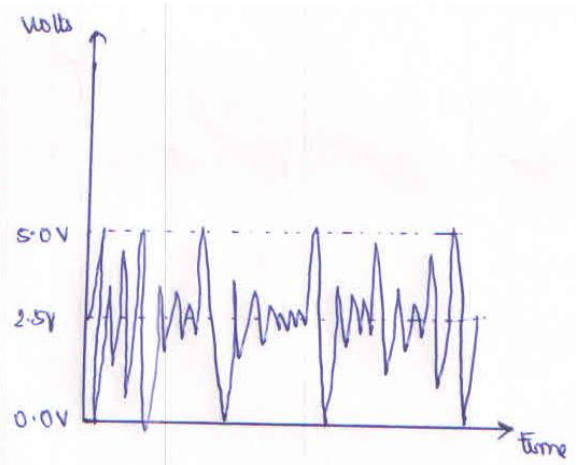

Fig1.8- Amplified Audio Signal ranging from 0 to $5 \mathrm{~V}$

The output of OP-AMP2 (pin 6) is than passed through resistor R7 (10k), which is a current limiter. This is done to prevent microcontroller from high voltages.

Capacitor $\mathrm{C} 4(0.1 \mu \mathrm{F})$ is a noise decoupling capacitor.

The output of the current limiter is applied to microcontroller. Here, PIC16F876 microcontroller is used. It is a 28 pin, 8-bit microcontroller. Pin description is shown is the Table 1 below

Table 1 - Pin description of PIC16F876

\begin{tabular}{|c|l|}
\hline Pin No. & Description \\
\hline 2 & Input from current Limiter \\
\hline 9,10 & Crystal Oscillator \\
\hline 19,28 & Ground \\
\hline 1 & $\begin{array}{l}\text { Memory Clear(Active lowpin) } \\
=1\end{array}$ \\
\hline 20 & Ycc \\
\hline 17 & Output of microcontroller \\
\hline
\end{tabular}

The output from pin 17 of microcontroller, which is a digital signal having an amplitude of $5 \mathrm{~V}$, is applied to a Voltage Regulator circuit consisting of a resistor and Zener Diode $\mathrm{Z}$ $(3.3 \mathrm{~V})$. This is done to reduce the amplitude from $5 \mathrm{~V}$ to $3.3 \mathrm{~V}$ since, the zigbee operates at $3.3 \mathrm{~V}$.

The down converted output of voltage regulator circuit is applied to Zigbee. Pin description of Zigbee is shown in Table 2 below:

Table 2- Pin description of Zigbee at Transmitter End

\begin{tabular}{|c|l|}
\hline Pin No. & \multicolumn{1}{|c|}{ Description } \\
\hline 3 & Down Converted Digital Data Input \\
\hline 1 & $V_{c c}$ \\
\hline 14 & Ground \\
\hline
\end{tabular}

\subsubsection{Hardware Description of Receiver}

\subsubsection{Power Supply Section}

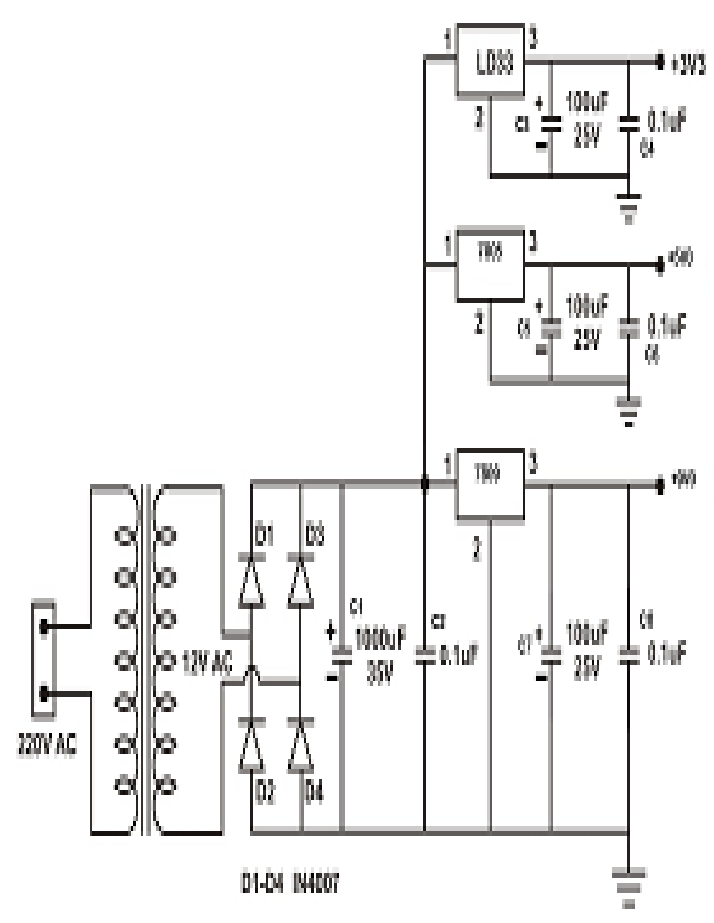

Fig1.9- Power Supply of Receiver

Here, at the input 220V AC supply is applied. This 220V AC is step down to $12 \mathrm{~V}$ AC using a Center tapped Step Down Transformer.

The $12 \mathrm{~V}$ AC supply is than applied to Full Wave Bridge Rectifier which converts it in $12 \mathrm{~V}$ Full Rectified AC signal using diode D1, D2, D3, D4 (1N4007X4). The output of Bridge Rectifier is applied across capacitor $\mathrm{C} 1(1000 \mu \mathrm{F}$, $35 \mathrm{~V})$, which is acting as main filter capacitor. The output of this capacitor is an unregulated $12 \mathrm{~V}$ DC signal. This unregulated $12 \mathrm{~V}$ DC is applied across capacitor C2 $(0.1 \mu \mathrm{F})$, which is acting as additional filter capacitor. The purpose of this capacitor is to remove noise from $12 \mathrm{~V} \mathrm{DC}$ line.

The $12 \mathrm{~V}$ DC signal is applied across IC LD33, IC7805 and IC7809. All the three ICs are three terminal Voltage Regulator ICs and their output are 3.3V DC, 5V DC and 9V DC respectively. Here, capacitor $\mathrm{C} 3(100 \mu \mathrm{F}, 25 \mathrm{~V})$ and $\mathrm{C} 4$ $(0.1 \mu \mathrm{F})$ remove the low frequency and high frequency noise from 3.3V DC line respectively. Capacitor C5 $(100 \mu \mathrm{F}, 25 \mathrm{~V})$ and $\mathrm{C} 6(0.1 \mu \mathrm{F})$ remove the low frequency and high frequency noise from $5 \mathrm{~V}$ DC line respectively. Capacitor $\mathrm{C} 7$ $(100 \mu \mathrm{F}, 25 \mathrm{~V})$ and $\mathrm{C} 8(0.1 \mu \mathrm{F})$ remove the low frequency and high frequency noise from 9V DC line respectively. 


\subsubsection{Reception Section}

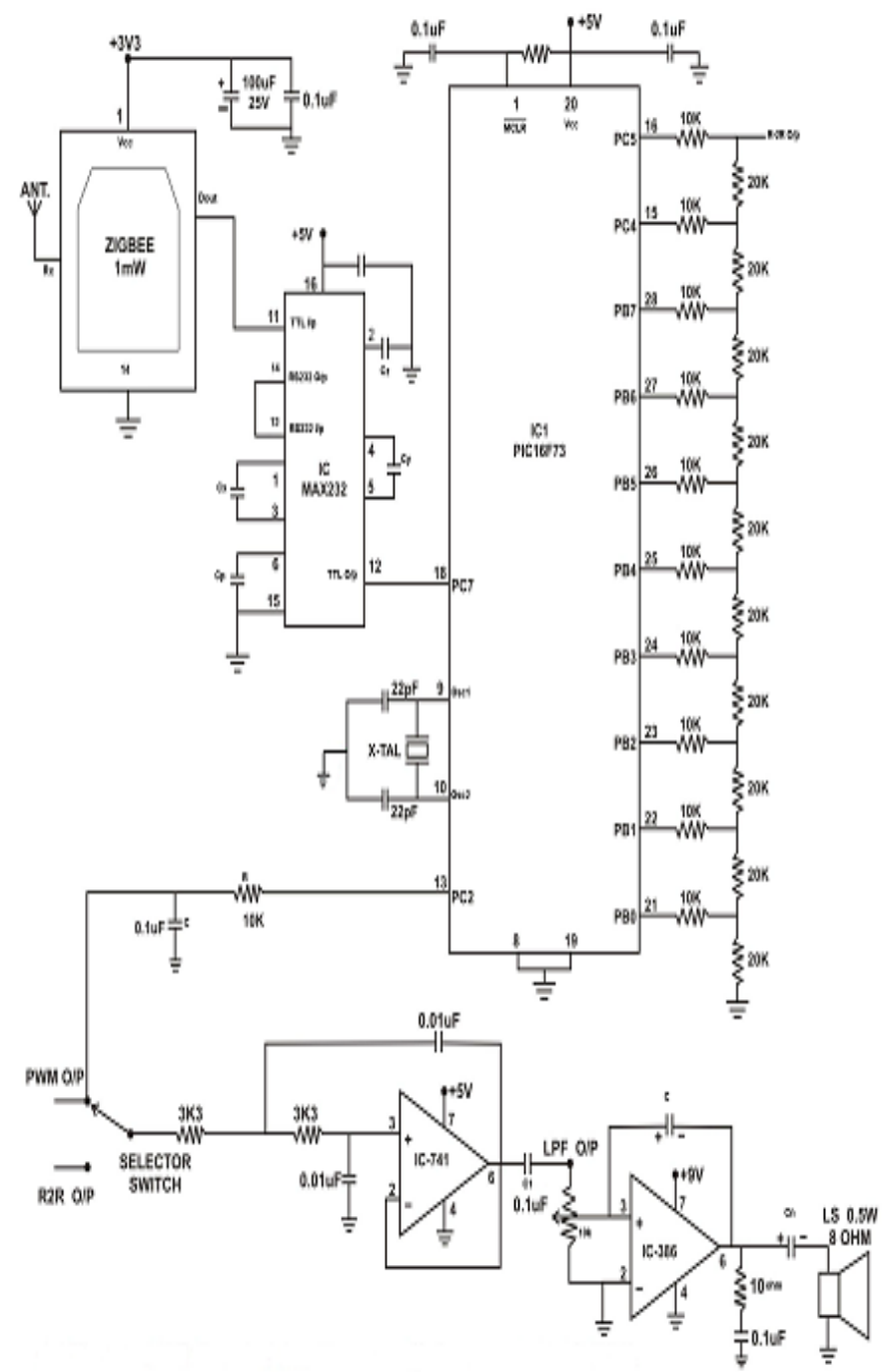

Fig1.10- Receiver Section of Receiver

At the receiver section, the $\mathrm{RF}$ antenna, receives the modulated signal and sends it to zigbee. Zigbee than demodulates the received signal.

After demodulation, the digital data signal, having an amplitude varying between $0 \mathrm{~V}$ and $3.3 \mathrm{~V}$, is than obtained at the output of zigbee.

The pin description of zigbee is shown in the table below:

Table 3 - Pin description of Zigbee at Receiver End

\begin{tabular}{|c|l|}
\hline Pin No. & \multicolumn{1}{|c|}{ Description } \\
\hline 1 & $V_{c c}$ \\
\hline 14 & Ground \\
\hline 2 & Down Converted Digital Data Output \\
\hline
\end{tabular}

Here, PIC16F73 micro controller is used which operates at $5 \mathrm{~V}$. But the output obtained from zigbee is a digital data signal having an amplitude varying between $0 \mathrm{~V}$ and 3.3V.Thus, the micro controller can not process the digital data. Therefore, it is required to increase the amplitude of digital data from $3.3 \mathrm{~V}$ to $5 \mathrm{~V}$. This is done by using IC MAX 232.

IC MAX 232 has CMOS compatibility. It has inbuilt TTL to S232 converter and RS232 to TTL converter.

In TTL logic:

Binary 0 is represented by Ground.

Binary 1 is represented by Vcc.

Similarly, in RS232 logic:

Binary 0 is represented by $-9 \mathrm{~V}$.

Binary 1 is represented by $+9 \mathrm{~V}$.

The pin description of IC MAX232 is shown in table 3 below:

Table 4- Pin description of IC MAX 232

\begin{tabular}{|c|l|}
\hline Pin No. & \multicolumn{1}{|c|}{ Description } \\
\hline 11 & TTL Input \\
\hline 14 & RS232 Output \\
\hline 13 & RS232 Input \\
\hline 12 & TTL Output \\
\hline
\end{tabular}

In the circuit capacitor $C_{X}, C_{Y}, C_{Z}, C_{P}$ are used for charge pumping in order to get $+9 \mathrm{~V}$ and $-9 \mathrm{~V}$ supply.

The output of MAX 232 is a digital signal having an amplitude varying between $0 \mathrm{~V}$ and $5 \mathrm{~V}$.

This digital signal is than applied to micro controller.

The pin description of micro controller is given in table 4 below:

Table 5 - Pin description of PIC16F73

\begin{tabular}{|c|l|}
\hline Pin No. & \multicolumn{1}{|c|}{ Description } \\
\hline 18 & Input from MAX232 \\
\hline 9,10 & Crysta1 0scillator (8 MHz) \\
\hline 8,19 & Ground \\
\hline 1 & Memory Clear(Active low pin) $=1$ \\
\hline 20 & Vcc \\
\hline $21-28,15,16$ & R-2R Resistors \\
\hline 13 & PWM Output \\
\hline
\end{tabular}

The PWM output of micro controller from pin 13 is than demodulated using a $\mathrm{RC}$ low pass filter $(\mathrm{R}=10 \mathrm{~K}, \mathrm{C}=0.1 \mu \mathrm{F})$. Also $-2 \mathrm{R}$ analog output is obtained from the $\mathrm{R}-2 \mathrm{R}$ junction as shown in Fig 1.10.

The two outputs (R-2R and PWM) are then connected through switch S.

According to the position of the switch, respective output is selected which is then passed though active low pass filter. 
The active low pass filter consists of an OP-AMP (IC741). The output of LPF is than passed through capacitor C1 $(0.1 \mu \mathrm{F})$, which blocks the DC component and allow pure audio signal to pass through it.

The output of capacitor $\mathrm{C} 1$ is applied across a volume control knob $(10 \mathrm{~K})$, which is used to set the amplitude of audio signal.

The amplitude of this audio signal is than amplified using audio amplifier IC LM386.

The output of audio amplifier is than applied across RC LPF $(\mathrm{R}=10, \mathrm{C}=0.1 \mu \mathrm{F})$, in order to remove the noise.

The output is than passed through coupling capacitor $\mathrm{C}_{\mathrm{N}}$ and than fed to the speaker $(0.5 \mathrm{~W}, 8 \mathrm{ohm})$.

\subsection{Experimental Results}

[A] The prototype of the system has been fabricated and tested. Figure 1.5 shows the transmitter module and Figure 1.6 shows the receiver module.

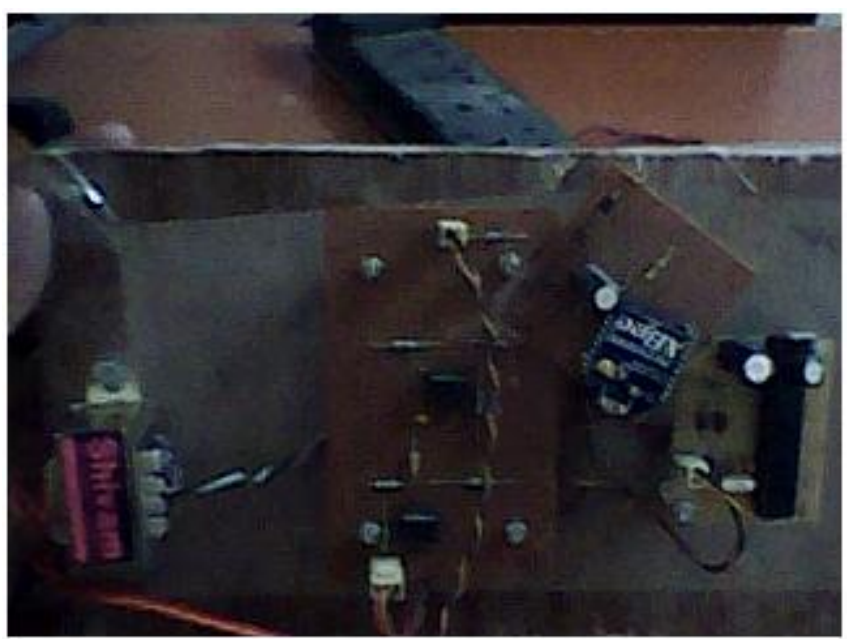

Fig1.11- Prototype of Transmitter

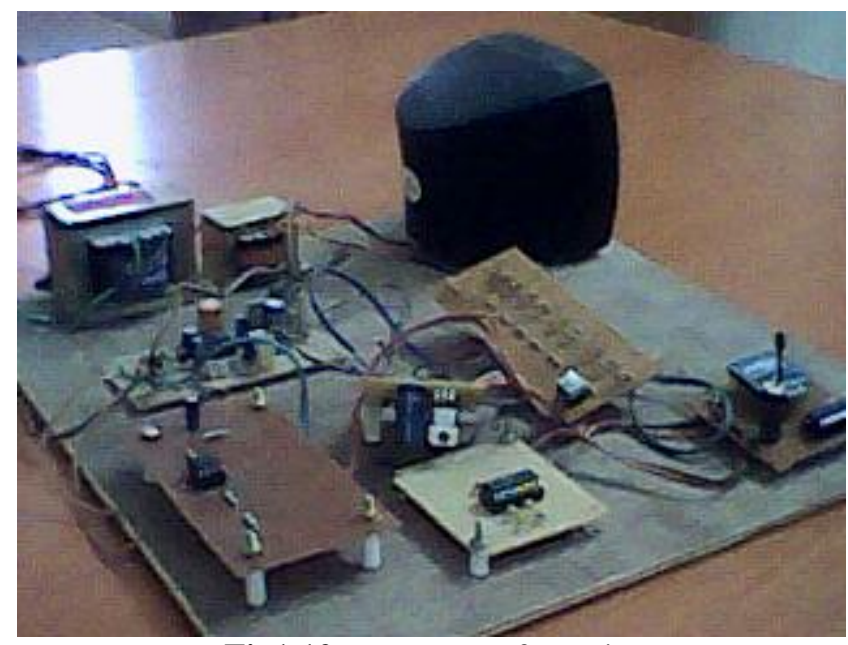

Fig1.12- Prototype of Receiver
[B] Figure 1.7 shows the waveforms taken at different terminals of the transmitter.

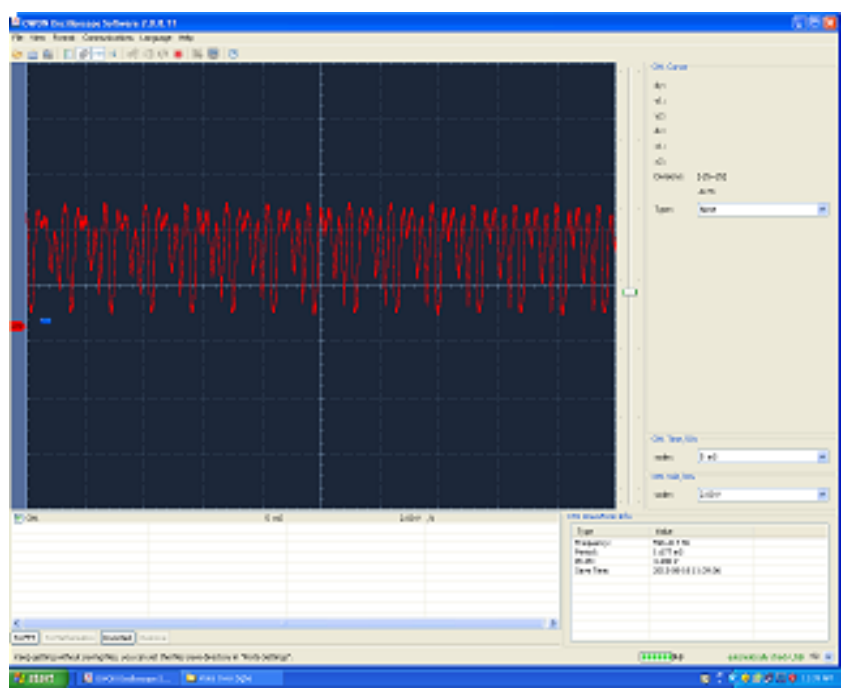

(a)

Transmitter Mic Input (5ms/div, 2V/div)

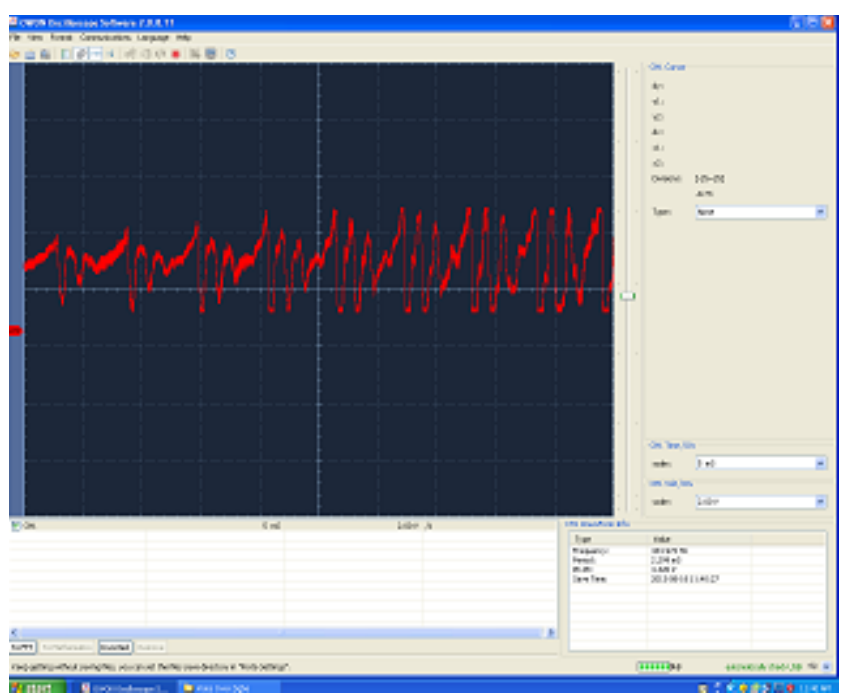

(b) Transmitter Amplifier Output(5msec/div, 2V/div)

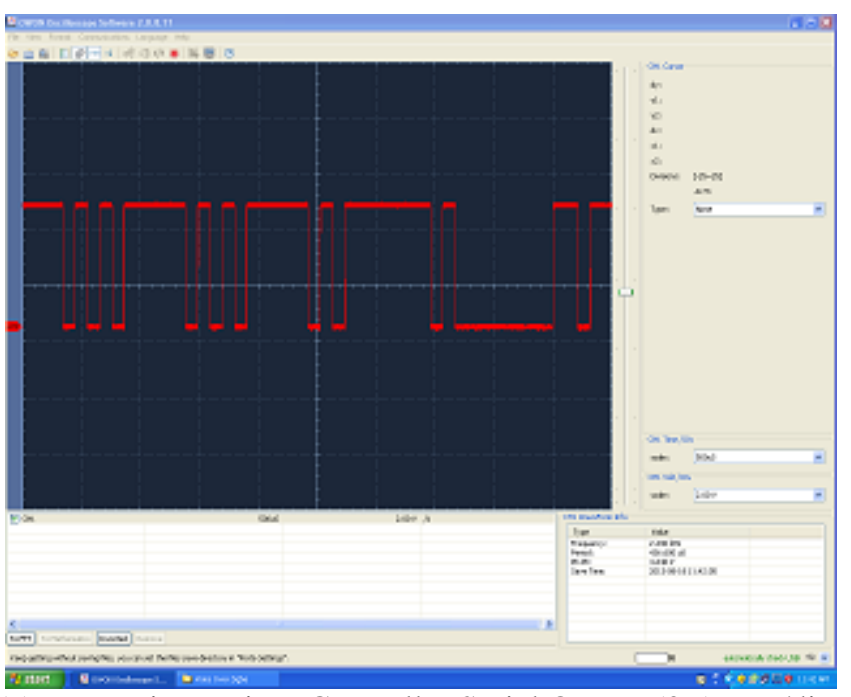

(c) Transmitter Micro Controller Serial Output $(0.5 \mathrm{msec} / \mathrm{div}$, $2 \mathrm{~V} / \mathrm{div}$ ) 


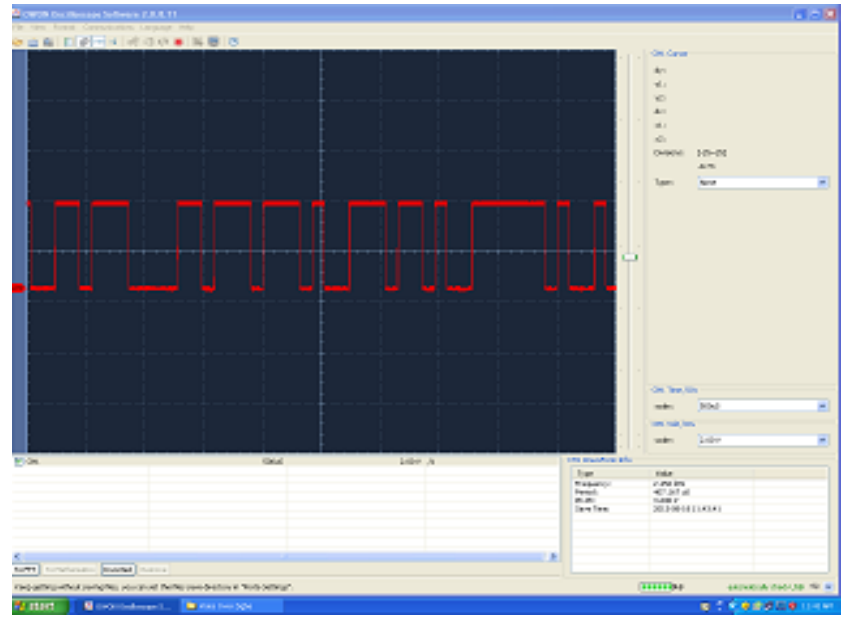

(d) Transmitter Zigbee Input Down converted to 3.3V (0.5msec/div, 2V/div)

Fig. 1.13 Waveforms at different terminals of Transmitter

[C] Figure 1.8 shows the waveforms taken at different terminals of the receiver.

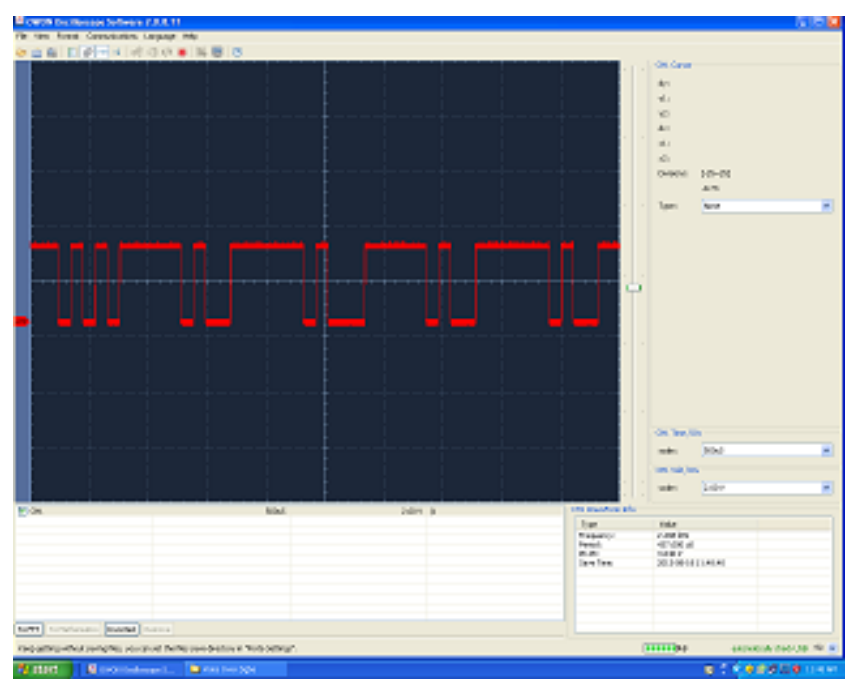

(a) Receiver Zigbee output at 3.3V (0.5msec/div, $2 \mathrm{~V} / \mathrm{div})$

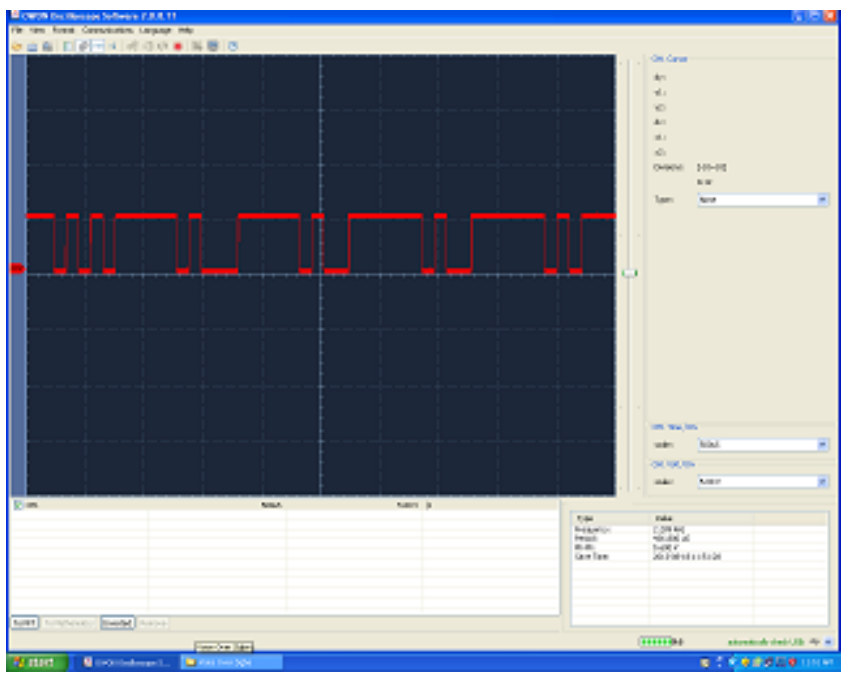

(b) Receiver Micro Controller Input (0.5msec/div, 5V/div)

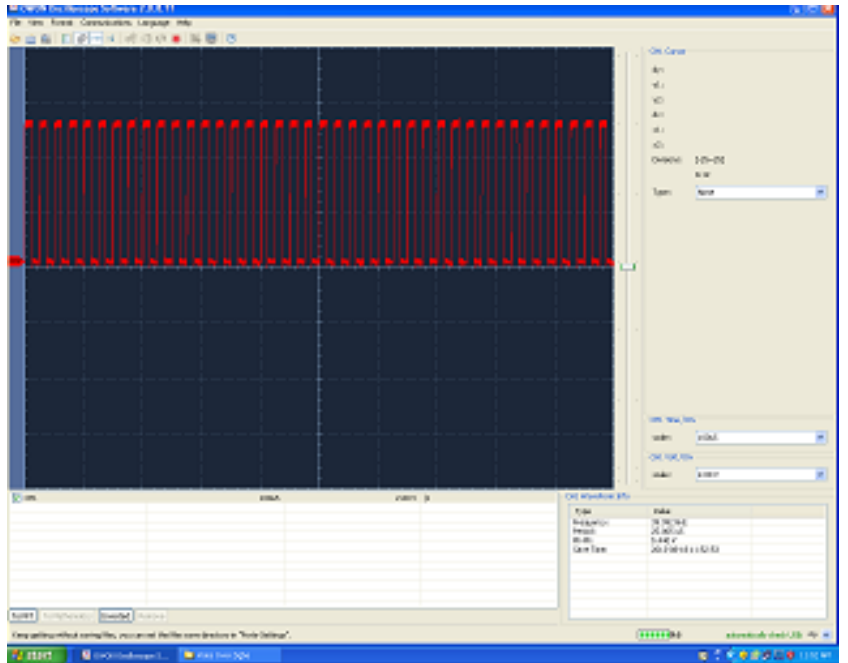

(c) Receiver Micro Controller PWM output $(0.1 \mathrm{msec} / \mathrm{div}$, 2V/div)

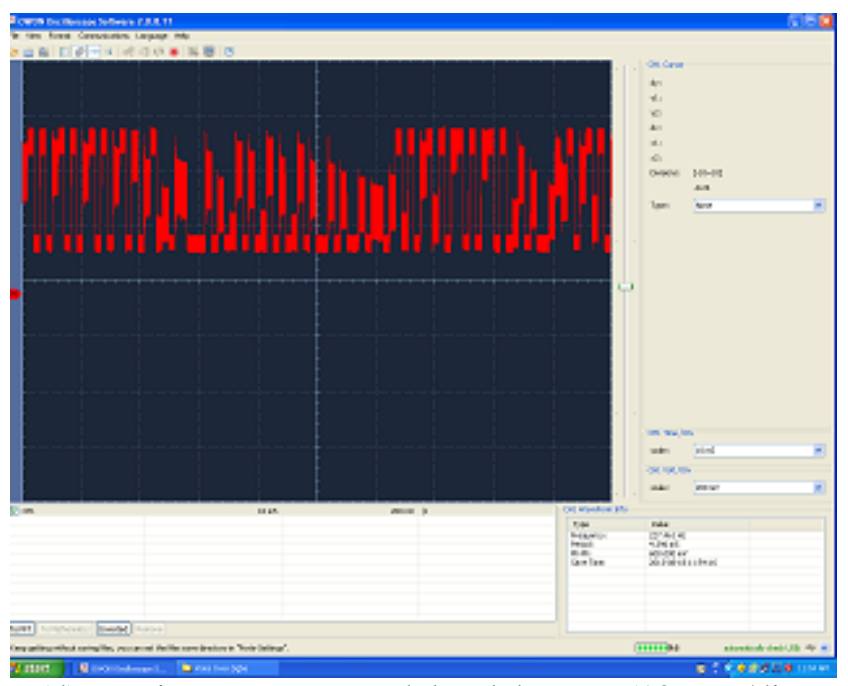

(d) Receiver PWM Demodulated by LPF (10msec/div, $0.2 \mathrm{~V} / \mathrm{div})$

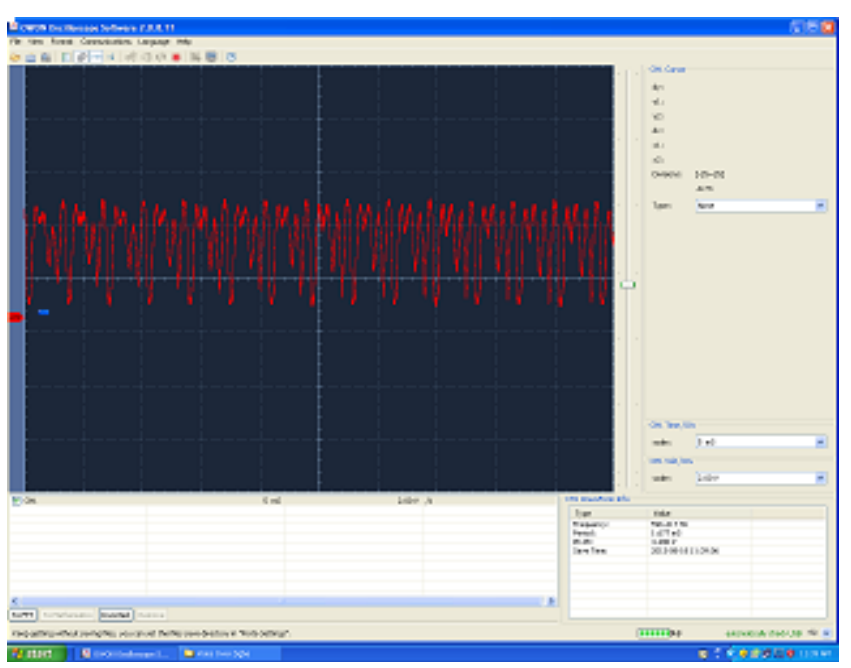

(e) Receiver R-2R Output (5msec/div, 2V/div)

Fig. 1.14 Waveforms at different terminals of Receiver 
The prototype was tested in a laboratory and it performed well up to $25 \mathrm{mts}$ with clear Line of Sight (LOS) transmission.

[D] Error Calculation :

Error Calculation is done for R-2R and PWM demodulated signals. Thus following conclusions are drawn from them:

(i) In case of R-2R DAC output, the maximum error occurred is $19.5 \mathrm{mV}$ which is very small in comparison to $5 \mathrm{~V}$.

(ii) The error in R-2R is occurring for 20 different amplitudes and zero for remaining amplitudes.

(iii) In case of PWM output, the error is varying non linearly and there is not a single amplitude for which the error is zero.

(iv) Thus, the voice quality of PWM generated output is less in comparison to R-2R DAC. The reason behind this is that, $\mathrm{R}-2 \mathrm{R}$ is a 10 bit DAC having a resolution of $4.88 \mathrm{mV}$ while PWM is a 8 bit DAC having a resolution of $19.5 \mathrm{mV}$.

\section{CONCLUSIONS}

Generally, Voice over Zigbee prototypes uses high speed Digital Signal Processors or 32- bit Micro Controllers. These prototypes have complex circuitry and are very expensive. Here, in this project we have made a prototype that uses low power 8- bit Micro Controller and Off the Shelf components, which makes it cost effective and easy for production. Because of its cost efficiency and ease of availability of components, it can be easily employed in circuits that uses voice communication.

\section{FUTURE PROSPECTS}

Future work will entail:

$>$ Use of High Speed Analog-to-Digital Converter (ADC), in order to improve the quality of voice.

$>$ By optimizing the circuit and making its dedicated chips using VLSI, the prototype on one hand will be more cost effective and on the other hand production can be increased to many folds.

\section{ACKNOWLEDGMENTS}

It is my pleasure and privilege to acknowledge and express my deep sense of gratitude to my guide, Ms. Sushila Chahar, (Asst.Professor), Department of Electronics \& Communication Engineering, JNIT, Jaipur, who inspired and initiated me to prepare this dissertation despite her busy academic schedule. She has always been kind enough to spare her valuable time and thought in giving necessary guidance. Her rich and varied experience as an academician immensely helped me in understanding this topic clearly. I express my sincere thanks to Mr. Ramesh Bharti, Asst. Professor Department of Electronics \& Communication Engineering, JaganNath University, Jaipur and Mr. Himanshu Bhojwani, Director, Contrivence IT Solution Pvt. Ltd. for their encouragement and diligent efforts in assisting me towards the implementation of this idea.

\section{REFERENCES}

[1]. Zigbee Alliance, Zigbee Specifications. Version 1.0 Zigbee Document 053474r06, December 14 ${ }^{\text {th }}, 2004$.

[2]. William Stalling, "Wireless Communication and network", Fourth Edition, Pearson Publication Limited, 2001, Pp39-118.

[3]. 802.15.4, Part 15.4: Wireless Medium Access Control (MAC) and Physical Layer (PHY) Specifications for Low Rate Wireless Personal Area Network (LRWPANs).

[4]. Andrew S. Tenenbaum, "Computer Networks", Fourth Edition Pearson Publication Limited, 2003, Pp 21-89.

[5].http://www.zigbee.org/en/documents/zigbeeoverview4.pd $\mathrm{f}$

[6]. http://www.palowireless.com/zigbee/tutorials.asp

[7]. http://www.zigbee.org/en/resources 